\title{
How ICTs shape the relationship between the State and the citizens: Exploring new paradigms between civic engagement and social innovation
}

\author{
Dimitri Gagliardi* \\ University of Manchester \\ Dimitri.Gagliardi@manchester.ac.uk \\ *Corresponding Author
}

\author{
Gianluca Misuraca \\ JRC - European Commission \\ Gianluca.MISURACA@ec.europa.eu
}

\author{
Francesco Niglia \\ Università del Salento \\ francesco.niglia@unisalento.it
}

\author{
Giulio Pasi \\ JRC - European Commission \\ Giulio.PASI@ec.europa.eu
}

\begin{abstract}
The paper investigates the role of Information and Communication Technologies (ICTs) in enabling social innovation and civic engagement. The purpose is to advance a typology for better understanding whether such a phenomenon might contribute to a paradigmatic shift in the relationship between the governments or the administrations and citizens. This framework is based on the review of recent literature on social innovation and ICTs, studying the relationships between government and citizens emerging from 41 cases. The analysis highlights how ICTs underpin innovation in civic engagement initiatives in two main ways: 1) by modernising existing processes and 2) by integrating new services.
\end{abstract}

\section{Introduction}

The concept of social innovation has been gaining attention in policy and academic debates experiencing a revival in the global policy agenda notably the Innovation Union Flagship Initiative and the Social Innovation Initiative in the European Union, the Office of Social Innovation and Civic Participation in the US and the forum on Social Innovation of the Local Economic and Employment Development of the OECD. Since the early 2000s the number of publications and policy reports has been growing at faster rates. The main aim of such literature was that of working out the concepts and the relationships between social innovation and other types of innovations with the objective to identify implications for theory building, management and policy [20].

A general way to define social innovation is "new ideas, products, services and models developed and implemented to meet social needs and create new social relationships or collaborations" ([16], p. 6). In other words, social innovations are both good for society and enhance society's capacity to act [32], while (i) implementing new ideas, services, production and organisational models to meet social needs, (ii) creating new social relationships as the objective of these factors and (iii) responding to social demand [5].

Within the European debate the idea of social innovation concerns mainly social services and the organisational setting for the ideation, development and delivery of social services of general interest which favour individuals' active participation to the social and economic life, of which active citizenship constitutes the underlying and underpinning condition. This aspect is considered one of the most important, shaping people's material living conditions and quality of life [1].

Civic engagement is a much debated concept, however it can be conceived as "the ways in which citizens participate in the life of a community in order to improve conditions for others or to help shape community's future” ([34], p.241). Civic engagement initiatives may include individual and collective forms of citizen engagement such as democratic participation and grass-root movements engaged in latent or manifest political participation [15]. For the purpose of this study we focus our attention on the emergent trend in digital forms of participation involving the coproduction of public services, [36], [10], [43]. In this domain, we are considering the role of ICTs as the enabler of those dynamisms that, facilitating and shaping the form of civic engagement, unleash social innovation initiatives.

In the next section we set out the theoretical background underpinning our study highlighting the rationale for social innovation, how digital services innovation may help us ground the theoretical foundations of ICT-enabled social innovation and the role of civic engagement. The research methodology and findings follow. Our reflection on the research concludes with a discussion of the typology obtained and highlights future directions for research.

\section{Theoretical background}

\subsection{Social Innovation from a 'quasi-concept' to a branch of innovation studies}


Social innovation, notwithstanding the increasing attentions is receiving, is still considered a 'quasiconcept' due to the fuzziness of its definition(s) and the fact that an epistemic community is only nascent [4], [31]. A recent contribution [13] traces the origin and evolution of the concept since its first appearance in the economic, managerial and policy debate [12] to the recent theories in development and innovation policy applied to processes of social change, sustainable development and to the social service sector. Recent studies [41] argue that modern social innovation research i.e. research conducted from the beginning of the 2000s, is polarising around 4 reference scholarly communities: 1) Community Psychology; 2) Creativity Research; 3) Social and Societal Challenges and 4) Local Development.

Despite some differences among the mentioned schools, social innovation may be seen as transformative or as a means to satisfy social needs that are otherwise unmet. In this broad framework, EdwardSchachter and Wallace [13], note a progressive shift of the Social Innovation theory towards its transformative attributes (systemic change) and a more 'applied' domain present in policy studies addressing societal needs through social services. Studies on social innovation have centred on actors (i.e. the importance of the third sector and social entrepreneurship) and their collaborative practices (i.e. collaboration between the third sectors, government and business) even though the mediation of technologies is lingering in the background as a paradigmatic approach liberating or building avenues for the realisation of social value.

Van der Have and Rubalcaba [41] provide further light regards the value-creation aspect of innovation which is common to the four social innovation schools. In the innovation studies tradition the value created is not always captured by the innovative actor: there are spillovers to society and, from studying value creation, social value and appropriability, the discipline could extend to studying the social impact of innovation.

2.1.1 Social innovation as value creation. Van der Have and Rubalcaba [41] suggest that looking at the loci of social value creation may provide insights into the social innovation process. In other words if social values are somehow hierarchical where society, with its basic institutional structures, provides general values (such as education, health and social care, and social support), communities' and citizens' values are produced and consumed on the basis of specific characteristics such as shared ethics. At these levels there is an apparent co-creation and exchange of value. While, in general terms, value generation and appropriation becomes a negotiated domain between public institutions and citizenships, a mismatch between the social services provided by society and those perceived essential by communities and citizens may provide room for different kind of social innovation (see [6]). It is in this context that civic engagement innovation becomes core to the present reflection. We will look at innovation and value creation in the digital services domain, focusing on the way civic engagement initiatives can be considered services enabled by ICTs connecting the state, in its role of provider, and the citizens as public services codesigners

\subsection{Digital service innovation}

Undoubtedly, in the last decade there has been an increasing focus on service research especially in conjunction with the development of ICTs. The trend is rather complex and deriving from the consideration that the growth of the service economy is impacting all sectors of social and economic activities. This growth is characterised by an increase in intra-organisational structures as well as inter-organisation networks of value creation. According to Barret et al [3], fundamental to the service innovation rapid and pervasive development is the widespread diffusion of ICTs as a crucial element for service delivery. Whilst traditional theories of service innovation consider ICTs as mere contributors to service efficiency, in reality their transformative role may be appreciated when considered as a resource in the service innovation process itself [24]. In other words, ICTs combined with other sources from which services originate i.e. knowledge and skills, allow information to be repackaged and transferred to other contexts and create new avenues for service innovation. ICTs may therefore have a creative role in the service innovation process rather than a simple assistive role.

The four dimensions of service logic, i.e. (1) service concept, (2) client interface, (3) service delivery system and (4) technology [19], [27], become central in the conceptualisation of service innovation. Any change in one sphere may trigger changes in the other connected dimensions and, depending on the degree of personalisation/formalisation of services, it may engender the formation of a new innovation ecosystem. These ecosystems, as argued by Lusch and Vargo [24], originate from the integration of resources and the exchange mechanisms that are institutionalised for the creation of value benefitting the parties involved. It is in these cases that ICTs assume an essential role in the creation and functioning of the ecosystem. At the same time, the ICT architectural infrastructure constitutes the means through which new or improved services are delivered [3]. In other words, approach to service innovation mediated through ICTs 
consists in re-bundling diverse resources to create a novel resource pool within the service ecosystem. Often these are mediated by service platforms [23]. In fact, the authors identified in ICTs, process and value proposition, the three main elements where integration of technologies, knowledge and skills become crucial for the design, development and delivery of service innovation. In this view, the role of ICTs in this framework can be interpreted in two ways: 1) as operand (or enabling), i.e. the static elements/ICT components enabling the service innovation process and 2) operant (or game-changing), the intangible ICT resources which are dynamic and triggering. The first kind produces efficiency in the service delivery process. Operant/game-changing ICTs are linked to the service concept, the delivery of services or the evaluation of the service performance and affect directly the related output and outcome processes.

2.2.1 ICT-enabled social innovation. Against these recent developments in digital service innovation, ICTenabled social innovation can be defined as "a new configuration or combination of social practices providing new or better answers to social protection system challenges and needs of individuals throughout their lives, which emerges from the innovative use of Information and Communication Technologies (ICTs) to establish new relationships or strengthen collaborations among stakeholders and foster open processes of co-creation and/or re-allocation of public value” ([29], p.8). This definition, according to the $\mathrm{S}$ D logic, considers ICTs as resources necessary to service innovation. Even more cogent, the role of ICTs in social policy innovation may be seen in the context of a citizen-centric approach to change in social practices and governance. This encompasses the provision of social services emerging from ICTmediated new processes where participation, design, delivery and fruition are based on trust [9], [28], [42].

\subsection{Civic engagement innovation}

Civic Engagement innovation is a long-debated concept in social and political sciences especially in connection with the effect of globalisation, the pervasive diffusion of ICTs and the change in population dynamics. Kim and Ball-Rokeach [21] report that there are at least two opposite interpretations of the recent status of civic engagement and the changes originating from these dynamics. One view argues that there is an ongoing decline in civic engagement while on the other side, many researchers and commentators argue that civic engagement is undergoing a restructuring process. In the first perspective, declining political party memberships, market or partisan-driven journalism (as opposed to public interest journalism [25]), public distrust of government and politics [17], and the weakening of the links between citizens and institutions are all indicators of this decline [40]. In the opposite view, it is argued that the restructuring process is evidenced by alternative means of engagement by citizens. These include significant growth in faith activities and movements, organisation of local/community-based activities, and participation to the global civil society or in virtual communities [40]. Importantly, the field was opened towards competition and users participation [7]. Opening to users and citizens implies engaging in more complex dynamics. In the 'old system' the service providers and the recipients were mostly engaged in simple transaction models (Normann [33] calls them "relieving logic" when a professional provide a service directly to the recipient). When, instead, the service is actually performed by the recipient, the service provider may be required to take an "active/enabling" role. In the 'new system', enabling-type of relationships would become increasingly more common establishing a new paradigm of co-creation. In the 1990s this trend became more evident, to the point that this logic permeated not just service delivery but also design and testing of new services, providing a larger platform for service innovation [2].

This had a twofold result. On one side, we assisted at an increase in competition, outsourcing and the formation of public-private partnerships [11]; on the other, we observes the transformation of the participative process with emerging structures such as 'citizen sourcing', 'government as platform' and 'do it yourself government' [22] (p. 449). The first stream consists in the study of a more institutionalised, yet dynamic, process where private and public sectors are engaged in the delivery of social services. The second stream provides an insight into citizen participation whereby civic engagement is paramount. The reason resides in the fact that critical aspects of the delivery of social services depend on the degree of participation and this is not homogenously distributed throughout the social strata. At the same time, the once-soleprovider of social services is changing the terms of the welfare state. In fact, according to Putnam [39], coproduction is most common in countries with a large welfare state. This means that co-production and strong state intervention in the welfare state are not substitutes; in order to work, this new setting would necessarily need long term government commitment as well as citizen participation or a civic culture [17].

This proposition is somewhat at dissonance with the current status of civic engagement described by Kim and Ball-Rokeach [21] and by Foa and Mounk 
[17]. Already in the 1990s, Ostrom stated that the juxtaposition of state and market or government and civil society is a 'conceptual trap' in that it limits our understanding of the complexity of human institutions [35] (p.1073). Trying to escape such trap, Meijer [26] highlights how co-production is the core principle of most forms of public service delivery.

2.3.1 ICT-based citizen engagement. Given the advances of ICTs, co-production might be moving to a different level and creating new possibilities for rearranging the relationship between government and citizens. In this context the third sector is posited to play a leading role in co-production of social services as well as constituting the social bridge by coalescing civic engagement in a longer term perspective [37]. The author, provides a conceptual framework and relative evidence according to which the importance of the third sector is exemplified by the fact that it operates by bridging the government, for profit organisations, and citizens engaged in co-production. Digital service innovation is thus a paradigmatic element in the innovation process [3] and it is redesigning the service system of innovation [11]. Increasingly, this ICTs-based paradigm is permeating the discourse on social innovation [8] and on social policy innovation [30], [18] with evident fallout on new/emerging forms of civic engagement.

\subsection{Links between ICTs based civic engagement and social innovation}

Civic engagement initiatives are considered ICTenhanced services whereby the technology enables a multi-level citizens-centric governance. Social impact is, therefore, ensured by new means of participation, design, delivery and fruition.

By means of the technology, civic engagement may assume many forms regulating relationships between citizens and government. A proto-classification of the potential links that can be mediated through technology was proposed by [18] (p. 164) whereby ICT-mediated citizen participation initiatives have been classified accordingly to the types of links between the citizens and their government (i.e. from unidirectional connections to feedforward and feedback mechanisms) and the type of technologies used to foster such links (i.e. types of technologies used, data types and visualisation options).

\section{Methodology}

The unit of analysis of the study consists in ICTenabled social innovation initiatives concerned with the design, development and implementation of service provision, systemic change and social policies in the domain of civic engagement. We focused on initiatives undertaken in the area of civic engagement in support of social policy reforms.

The research question underlying our work is 'how' ICT-enabled social innovation may foster the implementation of civic engagement initiatives through the provision of related services? Consequently we look at the combination of social innovation and ICTs and how these may serve the integration of procedures and approaches in the delivery of social services in the effort to modernise current civic engagement practices and promote new/emerging practices or services.

The initiatives analysed were extracted from the IESI Knowledge Map completed in late 2016 and published in 2017. The JRC-led IESI research developed a knowledge base of ICT-enabled social innovation initiatives across the EU and beyond. It collects and analyses in a structured manner over 600 initiatives across the EU. Circa 300 of the initiatives inventoried have been accurately mapped. The criteria for inclusion in the mapping exercise were 1) Policy relevance of the initiative - i.e. addressing or promoting civic engagement and social inclusion; 2) the Relevance of ICTs in delivering simplification and/or modernisation of social policy, administrative procedures or service delivery mechanisms and 3) Evidence of policy outcome or impact [30]. Evidence were collected through official evaluation reports, outcome self-reporting and interviews triangulated from third-party sources. These have been reviewed in at least two rounds by the IESI Team through a peerreview process, verifying that the criteria for inclusion were actually met. From this dataset of 300 documented initiatives spanning several areas of personal social services of general interest, we extracted 41 initiatives that had as a primary scope (or main activity) civic engagement.

This group of civic engagement social innovations present a great variety of initiatives involving grassroot movements and volunteerism as well as crowdsourcing/funding and citizen participation initiatives. They have a great variety in terms of geographical distribution since they are operating in 66 countries at a different level of geographical reach: 9 cases are active at the local level, 5 have a regional reach and the remainders are active at the national level. 1 initiative is transnational (i.e. active in 4 countries) yet it is deployed locally in 4 cities (local reach). There is high cross-cases variety in terms of size measured by the people involved: 12 initiatives are delivered by less than 10 people while 9 initiatives are provided by more than 50 people. These initiatives provide civic engagement services (27 out of 41), systemic change to civic engagement relationships or 
carry out a public policy. A further element of diversity concerns the ownership / governance of the initiatives. Only 3 initiatives have a private ownership/governance arrangement, 8 originate from the third sector and 10 are emanation of a public institution or agency. The remainders present mixed governance arrangements involving two or more actors from the three spheres.

The scope of our study is to provide an interpretative framework to further our understanding of integration between social service innovation and ICTs. Our objective is that of developing a typology that may serve this analytical purpose. Therefore, the methodology followed is qualitative so to understand 'how' and 'why' such initiatives are operating in the sector of civic engagement [44]. Moreover, we adopted a multiple case study framework to capture the variety of initiatives through which we can explore similarities and differences, drivers and challenges between cases. This methodology allows us to replicate our finding across different types of initiatives enhancing the validity of our typology [14].

\section{Findings}

\subsection{Characteristics of civic engagement initiatives: use of technologies}

The majority of the initiatives makes use of social networking technologies but very limited used of other types of ICTs. In particular, there are several initiatives relying exclusively on social media. Most grass-roots and citizen participation initiatives are often developed and run entirely through social networks; the first group is generally managed within flat hierarchies whilst the network is usually managed centrally. Initiatives promoting volunteerism, crowdsourcing and crowdfunding use also secure ID and financial eservices mainly to collect donations. On the other hand, initiatives providing specific public services, namely those directly launched and maintained by public agencies use exclusively secured platforms and e-services.

Unsurprisingly, these initiatives use ICTs to promote social and active participation, networking and engagement in the local community even though a small minority may use ICTs for other reasons such as promoting autonomy, self-expression, analysis and communication. ICTs are mainly used for front line services thus mediating interaction with and amongst citizens. About half of the initiatives also use ICTs for back office and case management.

Regarding the use of data, civic engagement initiatives operate with own data while only half of these also use external sources of data such as open/publicly available data or proprietary information. Only 3 initiatives use big data, and are engaged in crowdsourcing/funding.

\subsection{Characteristics of civic engagement initiatives: type of innovation}

The majority of initiatives is need-driven and outcome oriented. Their outcome is geared towards meeting the needs of society or of specific groups in society. Almost 3/4 of the initiatives are open to cocreation and engaged in collaborative innovation networks. In particular end-users and other stakeholders from the public, third or private sectors, are involved in the development, implementation and adoption of these innovations, each contributing their knowledge, resources, information and experience. Some 20 initiatives propose allocation and/or reallocation of public value in order to increase effectiveness and efficiency in meeting their objectives such as democratic citizenship. A group of initiatives of similar proportion propose fundamental changes in the relationships between stakeholders, establishing new relationships or institutional arrangements.

Circa 1/3 of the initiatives scoped use ICTs in a transformative way in order to support, facilitate or complement existing effort. In other words, the technology serves as a means to modernise or improve civic engagement through introducing new organisational mechanisms of services provisions. This implies changes at managerial, or governance and institutional level, such as the creation of new organisational forms, the introduction of novel management methods and techniques, and new partnerships or business/financial models. Examples of this type of innovation may be on-line consultations at the local or national level, match-making platforms where public participation may be used to direct attention to social issues or to access platforms for egovernment services. Initiatives in this category may be referred to as 'routine innovation'. (Exhibit 1).

\section{Exhibit 1. Example of routine social innovation}

Social Counter, Bologna: the system enables the operators to provide citizens with complete and timely information concerning a diverse portfolio of services they could be eligible for. Benefits brought by such one-stop-shop model are the reduction of waiting times and improved access to health and social services for citizens on one hand, and the simplification of administrative processes and continuity of care delivery among different levels of government on the other hand.

The majority of the initiatives scoped are involved in transformative innovation and ICTs are used to improve new services or create new mechanisms for service delivery which would be impossible otherwise. 
These initiatives are classed as disruptive innovations (Exhibit 2).

\section{Exhibit 2. Example of disruptive civic engagement innovation}

Make it Easy integrates the eParticipation concept in the creation of public services, allowing individuals, civil servants and private companies to exchange ideas, make suggestions for improvement, it welcomes comments on proposals by citizens, and co-create projects and solutions targeting the simplification of public administration. It achieved important results in terms of citizens' involvement, in widening access and take-up and improving the cost effectiveness of services.

In the same group, a smaller sub-set of initiatives uses ICTs outside the recognised institutional setting with the aim to radically modify the existing mechanisms of services provision (e.g. self-organised community to deliver services through social networks). This implies or leads to a paradigm shift that reframes the nature of specific problems, as well as their possible solutions. Examples of this type of innovation may be real-time information feeds, policy and government transparency platforms or multimedia platforms employed to build capacity and collaboration to enhance interest in active citizenship. It also includes ICT-based applications used to implement radically new ways of delivering services such as management and logistic mechanisms for food-waste without warehouses or collectors, or creating new social spaces through networking platforms by involving different stakeholders (Exhibit 3).

Exhibit 3. Example of radically new civic engagement innovation

GOTEO is a civic engagement platform focusing on creating a social network where different stakeholders can collaborate by making available funds, time and skills to implement projects, creating rewards oriented to the 'commons'. The collective returns are typically, knowledge sharing, free access to source code, training and didactic manuals, rough materials, files and digital content that can be replicated, reused and remixed..

Amongst the radically and disruptive innovative initiatives there is a small group that stands out since initiatives have the characteristics of both types.

Exhibit 4. Example of architectural innovation for civic engagement

CROSS provides innovative digital services to the "nonmonetary' economy, through the deployment of a digital transactional platform where citizens and organisations may interact for the provision of social services such as care for the elderly, social inclusion, employment/employability, education and learning and volunteering. The most interesting result is the actual upgrade of local policies in the social and public services provision and governance.

They focus on creating new mechanisms for service delivery as well as employing substantially new technologies to extract/provide value modifying existing mechanisms of service provision. Initiatives of this kind imply a re-framing of the nature of a specific problem that engender behavioural change in both provision and fruition of the services. We may think of these initiatives as architectural innovations [38] (Exhibit 4).

\subsection{Types of innovation and use of ICTs}

By relating the type of innovation with the role of ICTs in the service concept we obtain a clearer picture of the distribution of these initiatives. In particular, those initiatives using ICTs to update or optimise social services (i.e. digitalisation of analogue services) present a functional integration of ICTS: off-the-shelf ICTs are adopted and deployed in order to increase efficiency in the provision of services. Likewise, the level of innovation may stretch towards involving changes in the access and/or the provision of services. In these cases, the innovation process, though relying on the introduction of ICTs, has an impact on the organisation of the provision mechanisms. Changes in the management practices and governance may be associated to sustained innovation in the setting of civic engagement services. In these types of initiatives, ICTs have the role of operand/enabling, and their role is limited to supporting access and delivery of existing services in a more efficient way. Typically the technologies used in these cases consists in case management and back office technologies, which are often deployed in conjunction with rather basic front office applications enabling interaction with the beneficiaries. Moreover, the use of data is limited to those collected and collated in house which are often confidential.

On the opposite side of the spectrum, disruptive innovative applications favour the initiation of new services or the transformation of existing services. Disruptive use of new or customised ICTs in civic engagement services means that the services may not be possible in their analogue mode. This may be because of the increased participation and reach through ICTs which then reflects on the extent of the leverage of available resources. Typically, these initiatives are deployed upon platform-type or through social networking technologies. These usually allow a substantial level of interactivity between the service provider and the beneficiaries and in many cases are integrated with back-office application for the management of operations. The data used may include also linked or open data. Radically innovative use of ICTs may be the cause of emergence of new services or a transformation of the terms of relationships between providers and beneficiaries. In many cases, radical innovation in civic engagement takes place outside of the traditional institutional settings and tends 
to modify radically existing mechanisms of service provision.

This process is enabled by capitalising on those features of the ICTs that would in many cases constitute either the core idea or the fundamental principle upon which a service (or a group of services) may be thought out. In other words, the integration of new or customised ICTs directly in the idea of the services makes the services and the technology a unique new whole, a new service concept wherein ICTs may be understood as operant/game-changing. In a substantial minority of cases, the technology 'is' the service. These initiatives are typically based on multiple technologies merging social networking and platform-type technology with functions and applications enabling new ways of services fruition.

We have represented our findings in the Figure 1 below in order to highlight the relationships between the types of civic engagement innovation and the role of technology in users' empowerment.

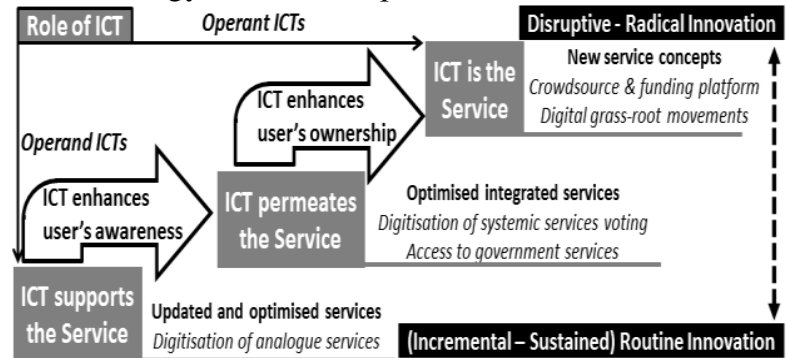

Figure 1. Types of social innovation and role of ICTs (Own elaboration)

4.3.1 Types of innovation and value creation What is the value-generation process in ICT-based civic engagement innovations according to the type of innovation and use of technology?

One common aspect amongst all initiatives is that value creation is generated only through interactions between service providers and beneficiaries (value of use) and mediated by ICTs. From our analysis it is evident that the potential for value creation may swing from 'simple' improvement of existing practices supported by an efficient use of ICTs (digitisation of analogues services) or the use of ICTs as a service, in fully fledged digital engagement services.

Even at the lowest level of value creation, we need to stress that the outcome of such initiatives are pervasive in terms of reach and effectiveness. Apart from the savings accruable through digitisation, increasing value may be created simply by increased services availability which becomes continuous and on-demand or by the automation of repetitive tasks that would enable an easier fruition. At the other end of the spectrum, value creation may be particularly evident. In those cases where technology is the core component of the initiatives, services may be provided virtually un-intermediated or at least with a high level of disintermediation. This means that effective civic engagement practices may be operated asynchronously following individual schedules independent from one another without impairing service delivery.

Between these two extremes, civic engagement initiatives may provide augmented value for citizens and government through changes in the organisation and management of pools of services across different levels of governance. They may provide avenues for value extraction through the application of new solutions to citizens and government needs. In other words, innovation dynamics spurred by the technological upgrade or the implementation of new solutions may favour disruptive civic engagement processes through the introduction of novel organisational settings or new avenues for value extraction/delivery in practices already in place.

\section{Discussion and conclusions}

At the inception of the paper we highlighted how civic engagement is a vast and varied area of study

\begin{tabular}{|c|c|c|c|}
\hline \multicolumn{4}{|c|}{ Exhibit 5. Comparison of ICTs use in different innovation types } \\
\hline Routine innovation & Disruptive innovation & Radical innovation & Architectural innovation \\
\hline $\begin{array}{l}\text { The ICT platform Social } \\
\text { Counter enables its staff to } \\
\text { retrieve reliable real-time data } \\
\text { concerning actual service } \\
\text { delivery, to manage services } \\
\text { directed to the same target } \\
\text { group based on need } \\
\text { assessment rather than on } \\
\text { service availability and to keep } \\
\text { unique records for each } \\
\text { individual case, granting the } \\
\text { possibility to assess the impact } \\
\text { of the delivered interventions. } \\
\text { ICTs: Case management, Back } \\
\text { Office, Frontline screen, Wikis } \\
\text { Data: Own confidential data }\end{array}$ & $\begin{array}{l}\text { Make it Easy consist in a } \\
\text { collaborative platform } \\
\text { including three areas for } \\
\text { individuals, entrepreneurs and } \\
\text { public officials: a virtual place } \\
\text { for proposal making and ideas } \\
\text { sharing, a collaborative cloud } \\
\text { for co-design and enrich shared } \\
\text { documents, a consultation area } \\
\text { for policy making. Different } \\
\text { private and public working } \\
\text { groups and debates characterise } \\
\text { the different access profiles. } \\
\text { ICTs: Social Networking, } \\
\text { Back office } \\
\text { Data: Linked data, Own data }\end{array}$ & $\begin{array}{l}\text { GOTEO provides advanced e- } \\
\text { services features embodied into } \\
\text { a platform for crowd } \\
\text { sourcing/funding and social } \\
\text { networking scopes, discussion } \\
\text { boards and data analytics. An } \\
\text { automatic tracking system } \\
\text { evaluating collective returns } \\
\text { achieved by funded projects } \\
\text { and a framework to evaluate in- } \\
\text { kind contribution to projects } \\
\text { complete the platform. } \\
\text { ICTs: Social Networking, } \\
\text { Online services } \\
\text { Data: Open Data, } \\
\text { Crowdsourced data, Own data }\end{array}$ & $\begin{array}{l}\text { CROSS deploys a digital } \\
\text { platform performing identity } \\
\text { management of users, transaction } \\
\text { management, reporting of non- } \\
\text { monetary indicators, service } \\
\text { exposure and discovery, semantic } \\
\text { framework, community } \\
\text { management. It embeds a light } \\
\text { block-chain procedure monitoring } \\
\text { the workflows of the services } \\
\text { providers in order to integrate and } \\
\text { streamline delivery and create the } \\
\text { conditions for the development of } \\
\text { new social services. } \\
\text { ICTs: Social Networking } \\
\text { Data: Crowdsourced data }\end{array}$ \\
\hline
\end{tabular}


including different initiatives with distinctive ownership and governance arrangements. Moreover, the pervasive nature of ICT-enabled social innovations in civic engagement manifests differently across various initiatives. These findings make this topic important in the field of Digital Government transformation, especially at the local and city level [22], [18] and have implications for research and policy. Four main findings may be outlined.

First: the role of ICTs in the creation of civic engagement - analysed in functional terms with respect to the contribution to the innovation potential of the service embodied in the initiatives - lead us to identify two main avenues through which ICTs are integrated. (i) ICTs are operand/enabler in terms of fostering efficiency and effectiveness in the delivery and fruition of services. ICTs are used to upgrade civic engagement providing a modern support structure upon which service delivery enables civic engagement (bottom half of figure 1). (ii) ICTs work as operant/game-changer as integral part of the service design [23] (top half of figure 1). In initiatives where ICTs have been fully integrated in the creation of new services or mechanisms for their delivery and fruition, we see that the ICT infrastructure, typical of the operand/enabling role of ICTs, is used as a basis upon which new services/mechanisms are created by leveraging on the role of operant/game-changing ICTs. This is evident when we analyse the initiatives under the lens of the service design logic [19], [27]. While sustained or incremental innovation provide the means for the initiative to update the organisation behind the delivery of services, radical or disruptive civic engagement manifests with the integration of new/customised technologies in all four phases of the service logic described in [19], [27] and in some case enable the creation of a new ecosystem [24] where integration of resources and delivery mechanisms may be institutionalised for the extraction/creation of new value for citizens and government.

Second: what is the expected role of ICTs? ICTs do not necessarily need to be cutting edge innovation to play a fundamental role in service provision. Well assessed and high performing ICTs might change the paradigm of a service, opening it to unexpected opportunities for managing public and private assets. This happens when ICTs act on the inner architecture of a service, changing the nature of interactions between core components, the intra-organisational levels, enabling new partnerships or business/financial models while reinforcing the core design concepts. In these cases, ICTs change the structure of a service allowing the inclusion of innovative features and additional means to create added value for the community. ICTs might also act as game changer, unveiling new collaborative social services. The adoption of block-chain or artificial intelligence is an example: the former aiming to provide transparency and accountability in the public services provision, while the latter is aimed at enhancing the interaction between citizens and services providers through the application of machine learning algorithms to linked open data. In the context of open data, services and decisions in the public sector through ICTs, the opportunity is offered to non-state actors to provide complementary services. We can think of this point as moving from the bottom left part of figure 1 towards the top-right.

Third: service integration and distributed governance/ownership are not characterised by a clear cut relationship between the ownership/governance and the innovativeness of civic engagement initiatives. One thing that became evident through the 41 cases is that the wider the governance arrangements, the higher are the potential avenues for innovation. For example initiatives spearheaded by ICT-savvy and innovationdriven social entrepreneurs are more likely to propose substantial civic engagement innovations than government agencies looking at efficiency savings. Though there are exceptions. For example, government agencies operating in highly digitised communities may be able to pass substantial reforms and deliver high-value civic engagement services. At the same time, traditional third sector organisations operating in digitally divided communities may be more conservative in the development of innovative services. It is important to understand the innovation push/pull forces operating within the ecosystem onto which the initiative is operating, and how these are conveyed by the social policy actors in order to identify a causal relationship. These observations may also be seen as the underpinning dynamics of ICT-enabled civic engagement initiatives in figure 1.

Fourth: different routes enable the integration of ICTs into civic engagement. One entails that ICTs are used to rationalise and increase efficiency in civic engagement services either through the digitisation of supporting activities that once were undertaken in an analogic mode (e.g. back office and case management) or through the digitisation of existing services so that its fruition by the beneficiaries may be enhanced (e.g. on line services access 24/7) - bottom-left corner of figure 1. Causing a shift of civic engagement from the 'real' to the 'digital' world, new dynamics in the design and deployment of services may entail changes both in the governance/ownership system and in the relationship between the provider and the citizens. Notably, re-organisation and new management practices are necessary to digitise these services and rarely appropriate capabilities are held in house by the 
service provider. Governmental agencies usually go through this process via procurement channels while initiatives led by third sector and private actors may be, at the beginning, of limited scope and then, once tried and tested, scaled up and rolled out for efficiency gains and rationalisation of services or through innovative multi-stakeholder partnerships. In this case, whilst we move from bottom-left part of figure 1 towards integrated services. A second route consists in the integration of ICTs within the service design providing new conceptual paradigms or new ways of organising service delivery. These cases, we argue, may follow more efficient and effective ways of providing value through applying novel ICT solutions enabling services in ways that otherwise would not be possible. We can position such services towards the top-right corner of figure 1. In both cases we can see that the role of ICTs is key for the delivery of the services. In some cases, ICTs embody the service. This class of civic engagement innovations are born digital. There is no experiential blue-print, therefore the relationship between government and citizens is designed by the provision-delivery-fruition of citizen engagement.

Finally we would like to spend a few words on the representativeness of the sample. Sample selection emerges from our need to understand and classify types of different social innovation initiatives in the civic engagement domain in terms of their innovativeness and the use they make of ICTs. Our objective was to collect evidence for drawing a typology of the phenomenon and this objectives has been amply met. The insights deriving may be validated through large-scale studies. Therefore, further studies, including replicability of our findings over other types of social innovations, would consolidate our conceptual construct.

The views expressed in this paper are purely those of the authors and may not in any circumstances be regarded as stating an official position of the European Commission.

\section{References}

[1] Adler, R. P., \& Goggin, J. (2005). What do we mean by "civic engagement"?. Journal of Transformative Education, 3(3), 236-253.

[2] Alford, J. (1998). A public management road less travelled: Clients as co-producers of public services. Australian Journal of Public Administration, 57(4), 128-137.

[3] Barrett, M., Davidson, E., Prabhu, J., \& Vargo, S. L. (2015). Service innovation in the digital age: key contributions and future directions. MIS quarterly, 39(1), 135-154.
[4] Bekkers, V.J.J.M., Tummers, L.G., Stuijfzand, B.G.; Voorberg, W. (2013). Social Innovation in the Public Sector: An integrative framework. LIPSE Working papers (no. 1). Rotterdam: Erasmus University Rotterdam

[5] Benneworth, P., Amanatidou, E., Edwards Schachter, M., \& Gulbrandsen, M. (2014). Social innovation futures: beyond policy panacea and conceptual ambiguity. European Forum for Studies of Policies for Research and Innovation.

[6] Borzaga, C., \& Bodini, R. (2014). What to make of social innovation? Towards a framework for policy development. Social Policy and Society, 13(3), 411-421.

[7] Bovaird, T. (2007). Beyond engagement and participation: User and community coproduction of public services. Public administration review, 67(5), 846-860.

[8] Bria, F., et al., (2014) Digital Social Innovation - Interim Report, NESTA

[9] Carter, L., \& Bélanger, F. (2005). The utilization of e-government services: citizen trust, innovation and acceptance factors. Information systems journal, 15(1), 5-25.

[10] Clark, B. Y., Brudney, J. L., \& Jang, S. G. (2013). Coproduction of government services and the new information technology: Investigating the distributional biases. Public Administration Review, 73(5), 687-701.

[11] Djellal, F., Gallouj, F., \& Miles, I. (2013). Two decades of research on innovation in services: Which place for public services?. Structural Change and Economic Dynamics, 27, 98-117.

[12] Drucker P.F. (1957) Landmarks of Tomorrow: A Report on the New Post-Modern World, Transaction Publishers New Brinswick and London, ed 1996

[13] Edwards-Schachter, M., \& Wallace, M. L. (2017). 'Shaken, but not stirred': Sixty years of defining social innovation. Technological Forecasting and Social Change, 119, 64-79.

[14] Eisenhardt, K. M., \& Graebner, M. E. (2007). Theory building from cases: Opportunities and challenges. Academy of management journal, 50(1), 25-32.

[15] Ekman, J., \& Amnå, E. (2012). Political participation and civic engagement: Towards a new typology. Human affairs, 22(3), 283-300.

[16] European Commission (2013). Guide to social innovation, Regional and Urban Policy. Brussels

[17] Foa, R S., and Y. Mounk. "The democratic disconnect." Journal of Democracy 27, no. 3 (2016): 5-17.

[18] Gagliardi, D., Schina, L., Sarcinella, M. L., Mangialardi, G., Niglia, F., \& Corallo, A. (2017). Information and communication technologies and public participation: 
interactive maps and value added for citizens. Government Information Quarterly, 34(1), 153-166.

[19] Hertog, P. D. (2000). Knowledge-intensive business services as co-producers of innovation. International journal of innovation management, 4(04), 491-528.

[20] Howaldt, J., Butzin, A., Domanski, D. \& Kaletka, C. (2014) Theoretical Approaches to Social Innovation - A Critical Literature Review. A deliverable by the project: "Social Innovation: Driving Force of Social Change" (SIDRIVE). Dortmund: Sozialforschungsstelle.

[21] Kim, Y. C., \& Ball-Rokeach, S. J. (2006). Civic engagement from a communication infrastructure perspective. Communication Theory, 16(2), 173-197.

[22] Linders, D. (2012). From e-government to wegovernment: Defining a typology for citizen coproduction in the age of social media. Government Information Quarterly, 29(4), 446-454.

[23] Lusch, R. F., \& Nambisan, S. (2015). Service innovation: A service-dominant logic perspective. MIS Quarterly, 39(1).

[24] Lusch, R. F., \& Vargo, S. L. (2014). The servicedominant logic of marketing: Dialog, debate, and directions. Routledge.

[25] McManus, J. H. (1994). Market-driven journalism: Let the citizen beware?. Sage Publications.

[26] Meijer, A. J. (2011). Networked Coproduction of Public Services in Virtual Communities: From a Government-Centric to a Community Approach to Public Service Support. Public Administration Review, 71(4), 598607.

[27] Miles, I. (2008). Patterns of innovation in service industries. IBM Systems journal, 47(1), 115-128.

[28] Misuraca, G. C. (2009). e-Government 2015: exploring m-government scenarios, between ICT-driven experiments and citizen-centric implications. Technology Analysis \& Strategic Management, 21(3), 407-424.

[29] Misuraca, G., Colombo, C., Kucsera, C., Carretero, S., Bacigalupo, M., \& Radescu, R. (2015). ICT-enabled Social Innovation in support of the Implementation of the Social Investment Package (IESI)-Mapping and Analysis of ICTenabled Social Innovation Initiatives promoting Social Investment through Integrated Approaches to the Provision of Social Services (No. JRC97467). Joint Research Centre.

[30] Misuraca, G., Kucsera, C., Pasi, G., Gagliardi, D., \& Abadie, F. (2017). ICT-Enabled Social Innovation to support the Implementation of the Social Investment Package. Mapping and Analysis of ICT-enabled Social Innovation initiatives promoting social investment across the EU: IESI Knowledge Map 2016 - The European Commission's science and knowledge service.
[31] Misuraca, G., Viscusi, G., \& Pasi, G. (2016). Digital Governance Challenges for ICT-Enabled Innovation of Social Protection Systems in the EU. In Electronic Government and Electronic Participation. IFIP EGOV and ePart 2016 (No. EPFL-CONF-221383, pp. 172-179). IOS Press.

[32] Murray, R., Caulier-Grice, J., \& Mulgan, G. (2010). The open book of social innovation. London: National endowment for science, technology and the art.

[33] Norman, R. (2001). $3^{\text {rd }}$ Ed. Service management: Strategy and leadership in service businesses. Wiley.

[34] OECD (2015), How's Life? 2015: Measuring Wellbeing, OECD Publishing, Paris.

[35] Ostrom, E. (1996). Crossing the great divide: coproduction, synergy, and development. World development, 24(6), 1073-1087.

[36] Pasek, J., More, E., \& Romer, D. (2009). Realizing the social Internet? Online social networking meets offline civic engagement. Journal of Information Technology \& Politics, 6(3-4), 197-215.

[37] Pestoff, V. (2012). Co-production and third sector social services in Europe: Some concepts and evidence. Voluntas: International Journal of Voluntary and Nonprofit Organizations, 23(4), 1102-1118.

[38] Pisano, G. P. (2015). You need an innovation strategy. Harvard Business Review, 93(6), 44-54.

[39] Putnam, R. D. (2000). Bowling alone: America's declining social capital. In Culture and politics (pp. 223234). Palgrave Macmillan US.

[40] Sloam, J. (2014). 'The outraged young': young Europeans, civic engagement and the new media in a time of crisis. Information, Communication \& Society, 17(2), 217231.

[41] van der Have, R. P., \& Rubalcaba, L. (2016). Social innovation research: An emerging area of innovation studies?. Research Policy, 45(9), 1923-1935.

[42] Warren, A. M., Sulaiman, A., \& Jaafar, N. I. (2014). Social media effects on fostering online civic engagement and building citizen trust and trust in institutions. Government Information Quarterly, 31(2), 291-301.

[43] Wehn, U., \& Evers, J. (2015). The social innovation potential of ICT-enabled citizen observatories to increase eParticipation in local flood risk management. Technology in Society, 42, 187-198.

[44] Yin, R. K. (2013). Case study research: Design and methods. Sage publications. 